\title{
Fluorescent Tagging of Polymer Particles with PBN for the Detection of Microplastics in Personal Care Goods
}

\author{
Eun-Hee Lee ${ }^{1,+\oplus} \cdot$ Sangwon Lee $^{2 \oplus} \cdot$ Seung-Woo Lee Le $^{2,3 \odot}$ \\ 'Department of Microbiology, Pusan National University, Republic of Korea \\ 2Department of Fine Chemistry, Seoul National University of Science and Technology, Republic of Korea \\ ${ }^{3}$ Department of Nano \& Bioengineering, Seoul National University of Science and Technology, Republic of Korea
}

(Received July 6, 2021; Revised July 27, 2021; Accepted July 27, 2021)

Objectives: Plastic pollution has been aggravated due to the massive use of disposable products and single-use face masks since the coronavirus disease (COVID-19) pandemic. There is growing interest regarding detection and identification of plastic pollution in daily life. The aim of this study is (1) to investigate suitability of a fluorescent labelling method for the detection of polymers, (2) to detect microplastics in personal care goods, and (3) to identify the detected plastic particles.

Methods: In order to detect plastic particles in real samples, a 1-pyrenebutyric acid N-hydroxysuccinimidyl ester (PBN) fluorophore was used as a dye for staining plastic particles. First, the capability of PBN was evaluated by staining a model polymer of polyethylene (PE) particles, and its desorption and photobleaching was also investigated. Using the optimum staining condition, microplastics were detected in a laboratory-controlled sample and commercially available products, specifically in cleansers, scrubs, and toothpastes. Finally, the detected microplastics were identified using an attenuated total reflection Fourier transform infrared spectroscopy (ATR FT-IR) analysis.

Results and discussion: The PE particles fluoresced blue light after being stained with PBN at a concentration of $100 \mu \mathrm{g} / \mathrm{mL}$ for $3-5 \mathrm{~min}$ without post treatments (e.g., fixation and drying), but the particles should be detected within $24 \mathrm{~h}$ due to the photobleaching of PBN. The desorption of PBN fluorophore occurred when the stained PE particles were washed with $25 \%$ acetone rather than rinse-off with deionized (DI) water. All of the tested personal care goods contained plastic particles and various sizes and shapes (e.g., spherical, rounded, and irregular shapes) of particles were found in different types and brands of products. The detected particles were identified as PE, polypropylene (PP), polycarbonate (PC), ethylene vinyl acetate (EVA), polystyrene (PS), and polyvinyl chloride (PVC) polymers.

Conclusions: The PBN was shown to effectively stain polymer particles and it allowed visual identification of microplastics in personal care goods. Various types and sizes of polymers were included into the commercially available products as ingredients, indicating a primary source of plastic pollution in aquatic environment.

Keywords: Polymer Particle, Staining, Screening Method, Commercially Available Product

Corresponding author
E-mail: leeeh@pusan.ac.kr
Tel: +82-51-510-2981 Fax: +82-51-514-1778
(c) 2021, Korean Society of Environmental Engineers

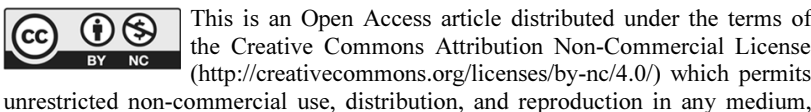
unrestricted non-commercial use, distribution, and reproduction in any medium, provided the original work is properly cited. 


\section{Introduction}

Plastic pollution has become a global problem and one of the most serious threats to natural ecosystems. ${ }^{1)}$ According to the Plastics-the Facts 2017 report, while the estimated global plastic production was 335 million tonnes in 2016, only 27.1 million tonnes of plastic waste were collected for post-consumer waste treatment. ${ }^{2)}$ Nearly $90 \%$ of plastic products were used once and then discarded. ${ }^{3)}$ The vast majority of plastic waste has accumulated in landfills or the natural environment. ${ }^{4)}$

The coronavirus disease (COVID-19) pandemic has significantly aggravated the situation of waste generation worldwide. ${ }^{5,6}$ The World Health Organization (WHO) has highly recommended the public using personal protective equipment (PPE) to prevent transmission of respiratory disease such as COVID-19, and requested a $40 \%$ escalation of single-use PPE production. ${ }^{7,8)}$ The lightness, durability, and versatility of plastics make them suitable for the application in medical tools and equipment. ${ }^{6}$ ) The plastic-based PPEs have mostly used as face masks, gloves, and medical gowns. Assuming one disposable face mask per day, the global population could monthly consume and generate the waste of 129 billion single use face masks and 65 billion gloves. ${ }^{89}$ ) The COVID-19 pandemic has posed an environmental burden in terms of plastic waste management, especially mismanaged plastic waste is likely to enter the oceans via runoff, wind, or tidal transport. ${ }^{5)}$

Plastics undergo environmental weathering (e.g., ultraviolet radiation, photooxidation, mechanical forces, etc.) and break up into small pieces during the degradation processes. ${ }^{10-12)}$ Recently, the interest towards microplastics (synthetic polymer particles less than $5 \mathrm{~mm}$ ) has been growing among the public due to their widespread discovery from Arctic to the tropics and from Mount Everest to deep ocean floors. ${ }^{13-17)}$ Microplastics are classified into primary source that originally manufactured to small size and secondary source when fragmented from larger plastic items. Smaller plastic debris can transfer to cellular membrane of the organisms and be passed up to higher levels through trophic transfer in the food chain. ${ }^{18)}$ The laboratory-scale experiments showed the uptake of primary microplastics in various organisms including zooplankton, bivalves, invertebrates, and fish. ${ }^{14,19,20)}$

So far, a lot of studies reported plastic pollution in environment especially in the ocean, but mostly focused on the plastic pollution caused by secondary microplastics. ${ }^{21,22)}$
Despite of the importance of primary source, there has been a relatively lack of studies regarding the plastic pollution of primary microplastics.

In this study, we evaluated microplastics in commercially available products using a 1-pyrenebutyric acid N-hydroxysuccinimidyl ester (PBN) fluorophore. ${ }^{23)}$ First, the staining capability of $\mathrm{PBN}$ was investigated using polyethylene (PE) particles as a target polymer. The suitablility of PBN as a dye for staining plastic particles was verified by analyzing its desorption and photobleaching. Finally, microplastic particles were detected using a PBN fluorophore in a laboratory-prepared sample and commercially available products, specifically cleansers, scrubs, and toothpastes. The sizes and shapes of microplastics were determined with assistance of fluorescence microscopy. The material of polymer particles was identified using an attenuated total reflection Fourier transform infrared spectroscopy (ATR FT-IR) analysis.

\section{Materials and methods}

\subsection{Fluorescent tagging of polymer particles with various concentrations of PBN}

Aliquots $(1 \mathrm{mg})$ of PE $(<500 \mu \mathrm{m}$, Sigma-Aldrich, St. Louis, $\mathrm{MO}$, USA) powder were transferred to polycarbonate track-etched (PCTE, $0.4 \mu \mathrm{m}, 47 \mathrm{~mm}$, Merck Millipore Ltd., Burlington, MA, USA) membranes, in which soaked in 200 $\mu \mathrm{L}$ of deionized (DI) water as a simulation of water filtration. The solutions of PBN (Santa Cruz Biotechnology Inc., Dallas, TX, USA) were prepared in $25 \%$ acetone to desired concentrations of $0,5,10,25,50,100$, and $200 \mu \mathrm{g} / \mathrm{mL}$, respectively. Subsequently, aliquots of a fresh PBN solution $(100 \mu \mathrm{L})$ were added to the PE powder on the wet PCTE membranes. As a negative control, a volume of $100 \mu \mathrm{L}$ of a solution of $25 \%$ acetone was added to a separate membrane containing PE powder. The membranes were incubated for 5 min in the dark, and then placed on a microscope stage for taking optical and fluorescence images (Leica MZ10 F, Leica Microsystems Ltd., Wetzlar, Germany). The samples were viewed under a DAPI filter set (excitation at wavelengths from 325-375 nm and emission at 435-485 nm) with exposure time of $5 \mathrm{~s}$ and 5 gains. This observation conditions of fluorescent microscopy were employed in other experiments. The fluorescence intensities of the samples were quantified using the Leica application suite (LAS) program (Leica Microsystems). The median intensities of the polymer particles 
and their surrounding background were employed for comparison.

\subsection{Effects of the duration of staining using the PBN solution on the fluorescent tagging of the polymers}

PBN solution was freshly prepared in $25 \%$ acetone to a concentration of $100 \mu \mathrm{g} / \mathrm{mL}$, and the solution was filtered using a polytetrafluoroethylene syringe filter (PTFE, $0.22 \mu \mathrm{m}$, Whatman, GE Healthcare Life Sciences, Santa Clara, CA, USA) prior to use. Aliquots $(100 \mu \mathrm{L})$ of $\mathrm{PBN}$ solution were added to wet PCTE membrane samples each containing $1 \mathrm{mg}$ of PE powder. The samples were incubated in the dark for different durations, specifically $0.5,1,3,5,15$, and $30 \mathrm{~min}$. Each respective membrane was transferred to a microscope stage for acquiring optical and fluorescence images of the PE particles. The samples were viewed under a DAPI filter set as described earlier.

\subsection{Desorption and photobleaching of PBN-labelled polymers}

Aliquots $(100 \mu \mathrm{L})$ of pre-filtered $100 \mu \mathrm{g} / \mathrm{mL}$ PBN were added to the wet PCTE membranes containing $1 \mathrm{mg}$ of PE powder, and the membranes were stained for $5 \mathrm{~min}$ in the dark. Optical and fluorescence images of the labelled PE particles were then taken. Subsequently, the PE particles on the membranes were washed with DI water or a $25 \%$ acetone solution. For photobleaching tests, PE particles on the PCTE membrane were stored at ambient temperature in the dark. Fluorescence microscopy images of these PE particles were taken in the same manner as described above.

\subsection{Fluorescence detection of spiked polymer particles in a laboratory-prepared sample}

A laboratory-controlled sample was prepared using a mixture of polymers, specifically polyethylene (PE), poly (ethylene terephthalate) (PET, $300 \mu \mathrm{m}$, powder, Goodfellow Cambridge Ltd., Huntingdon, UK), polyvinyl chloride (PVC, $250 \mu \mathrm{m}$, Goodfellow), polyamide-6(PA-6, nylon-6, 15-20 $\mu \mathrm{m}$, Goodfellow), polypropylene (PP, $3 \mathrm{~mm}$, Goodfellow), polystyrene (PS, 900 $\mu \mathrm{m}$, Goodfellow), polycarbonate (PC, $3 \mathrm{~mm}$, Goodfellow), polyvinylidenechloride (PVDC, $<180 \mu \mathrm{m}$, Goodfellow), and polyurethane (PU, 1.5-3 mm, Goodfellow). Ten milligrams (10 $\mathrm{mg}$ ) of each polymer were spiked into a $200-\mathrm{mL}$ glass vial containing $100 \mathrm{~mL}$ of tap water supplemented with $0.1 \%(\mathrm{v} / \mathrm{v})$ Tween 20 (Sigma-Aldrich). The mixture of polymer particles was homogeneously dispersed by agitating the vial for $30 \mathrm{~min}$ with shaking of $100 \mathrm{rpm}$. Aliquots of this laboratory-controlled sample were filtered through the PCTE membrane $(0.4 \mu \mathrm{m}$, $25 \mathrm{~mm}$, Sterlitech Co., Kent, WA, USA). After filtration, the membrane was washed with DI water to remove residual Tween 20. The filtered polymer particles were stained using $100 \mu \mathrm{L}$ of $100 \mu \mathrm{g} / \mathrm{mL}$ PBN for $5 \mathrm{~min}$ in the dark. Fluorescence images and optical images of the polymer particles were acquired using the microscopy as described above.

\subsection{Detection of microplastics in commercial products}

Four samples (designated as A, B, C, and D) of each of three commercially available products, namely a cleanser, scrub, and toothpaste were chosen for the detection of microplastics in them. Aliquots $(0.2 \mathrm{~g})$ of the cleanser, scrub, and toothpaste were each transferred into respective $50-\mathrm{mL}$ glass vials containing $10 \mathrm{~mL}$ of DI water, and then subjected to incubation at ambient temperature for $30 \mathrm{~min}$ with shaking at $100 \mathrm{rpm}$. A volume of $100 \mu \mathrm{L}$ of each solution was filtered through a PCTE membrane, which was washed with $10 \mathrm{~mL}$ of DI water. Each respective membrane was stained with PBN in the same manner as described above. After staining, the detection of PBN-labelled microplastics using fluorescence microscopy applied to all the consumer products. The sizes and shape of microplastics were determined from the fluorescence images.

\subsection{Cross validation and identification of microplastics in commercial products}

ATR FT-IR spectra of each cleanser, scrub, and toothpaste sample were collected using an Agilent Cary 630 FTIR (Agilent Technology, Santa Clara, CA, USA) from 4,000 to $648 \mathrm{~cm}^{-1}$ with a resolution of $4 \mathrm{~cm}^{-1}$. A background scan was carried out between each sample, and the IR spectra were baseline-corrected.

\section{Results and discussion}

\subsection{Effects of PBN concentration on the fluorescent tagging of polyethylene (PE) particles}

The PBN fluorophore was capable of staining the PE polymer (Fig. 1). ${ }^{23)}$ The PE particles labelled with $\mathrm{PBN}$ were able to fluorescently emit blue light, and the fluorescence images accurately corresponded to the optical images of PE (Fig. 1 and S1). Note that PE particles not stained with PBN (PE polymer only) showed insignificant levels of blue-light fluorescence. ${ }^{23)}$ The fluorescence of the stained PE polymer 


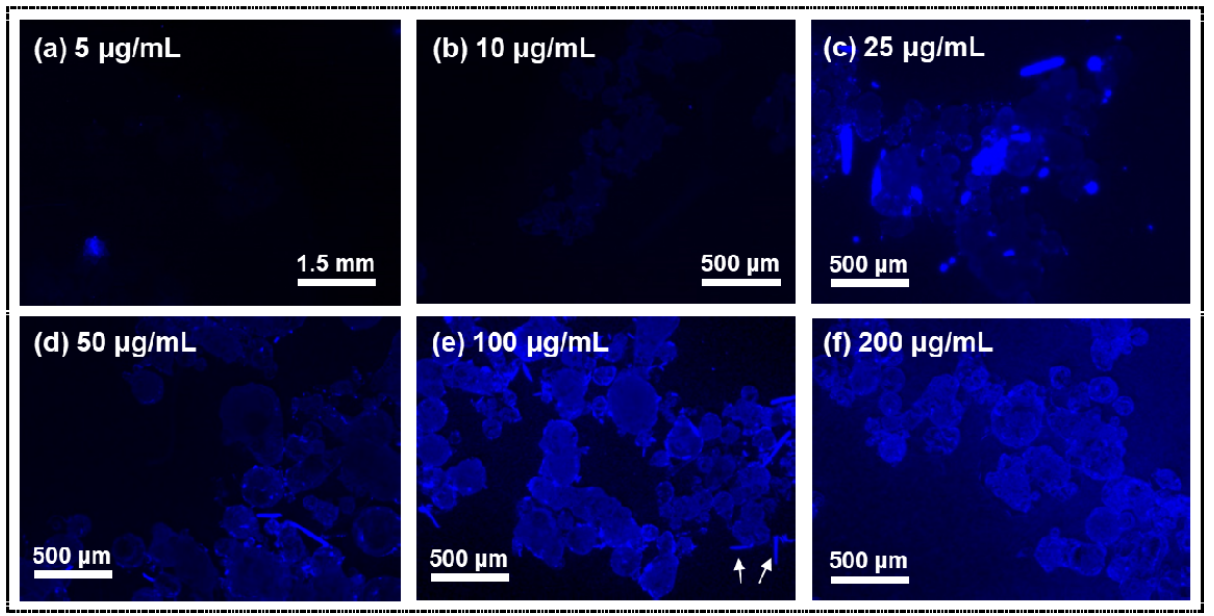

Fig. 1. (a-f) Fluorescence images of polyethylene (PE) polymer stained for $5 \mathrm{~min}$ with various concentrations of PBN, specifically (a) 5, (b) 10, (c) 25, (d) 50, (e) 100, and (f) $200 \mu \mathrm{g} / \mathrm{mL}$. The arrows indicate precipitates of PBN.

was dependent on the concentration of the PBN fluorophore. PE particles stained with PBN concentrations up to $10 \mu \mathrm{g} / \mathrm{mL}$ were difficult to discern using fluorescence microscopy (Fig. 1(a) and 1(b)). On the other hand, the fluorescent PE particles incubated with $25 \mu \mathrm{g} / \mathrm{mL}$ PBN were clearly observed, and PE polymer became more distinctly identified as the concentration of PBN was increased further (Fig.1(c)-(f)). In particular, the shapes of the PE particles incubated with $100 \mu \mathrm{g} / \mathrm{mL}$ PBN were readily distinguished, and the median fluorescence intensities of the PE particles and background were here measured to have relative fluorescence unit (RFU) values of, respectively, 2,755 \pm 111 and 1,439 \pm 62 (Fig.1(e) and S1(g)). PE polymer labelled with $200 \mu \mathrm{g} / \mathrm{mL}$ PBN showed the strongest median fluorescence intensity of 3,160 \pm 83 RFU, but the background fluorescence intensity was also increased to $1,871 \pm 207$ RFU (Fig. 1(f) and S1(g)). In the images of the PE particles, rod-shaped precipitates (marked with arrows of Fig. 1(e)) attributed to PBN were often detected, indicative of the need to remove precipitates of PBN in order to reduce the number of false positives. These results taken together indicated that the concentration of PBN must be greater than $50 \mu \mathrm{g} / \mathrm{mL}$ in order to achieve a highly sensitive detection of microplastics stained by PBN. Accordingly, $100 \mu \mathrm{g} / \mathrm{mL}$ PBN was used in the subsequent experiments.

\subsection{Effect of the duration of incubation with the PBN solution on the staining of polyethylene (PE) particles}

PBN labelling of PE polymer was dependent on the duration of the incubation (Fig. 2 and S2). Interestingly, PE particles could be stained with PBN fluorophore in a short period of time, specifically only $30 \mathrm{~s}$ (Fig.2(a)), and $3 \mathrm{~min}$ of incubation was sufficient for achieving an effective staining of the microplastics (Fig. 2(c)). The fluorescence intensity of the PE particles significantly increased as the incubation time was increased beyond $3 \mathrm{~min}$, but the fluorescence intensity did not significantly change any further when the incubation time was increased beyond $5 \mathrm{~min}$ (data not shown). These results demonstrated the ability of the PBN fluorophore to coat microplastics rapidly and showed that only a short period of incubation time, 3-5 min, was required to achieve an effective fluorescent tagging of the tested microplastics using PBN. These results also contrasted with the longer previously reported 10-120 min of incubation required when using other fluorophores. ${ }^{24-27)}$ Our results taken together thus indicated that the newly proposed PBN fluorophore allowed for a rapid detection of PE particles, and that this rapid detection was associated with the high affinity of PBN for the PE polymers.

\subsection{Desorption and photobleaching of fluorescent tags on polyethylene (PE) particles}

Insignificant amounts of PBN molecules were removed from the stained PE particles as a result of washing them with DI water (Fig.3). After three to five cycles of DI water washing, the median intensities of fluorescently tagged PE particles were marginally different from that without washing (Fig. 3(d)). On the other hand, desorption of PBN molecules from the PE polymer occurred when the rinsing was carried out with a solution of $25 \%$ acetone (Fig. 4): the fluorescence signal from the PE polymer decreased by $84 \%$ after it was washed with $25 \%$ acetone five times (Fig. $4(\mathbf{e})$ ). This result was 


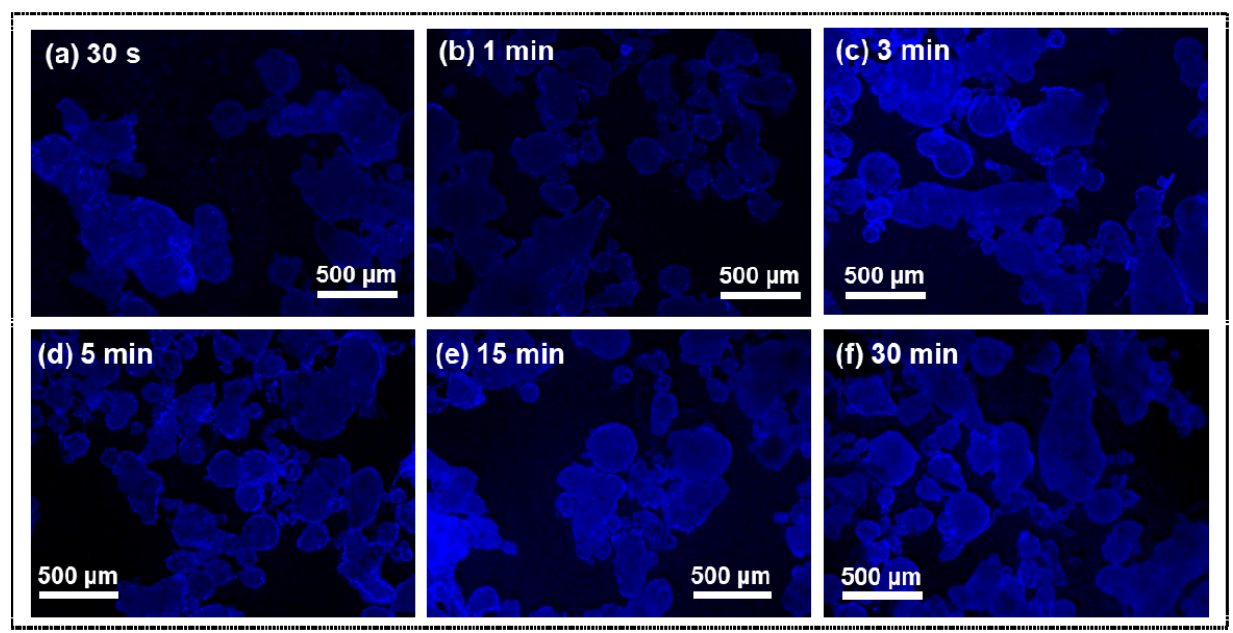

Fig. 2. Fluorescence images of polyethylene (PE) particles stained with the PBN fluorophore of $100 \mu \mathrm{g} / \mathrm{mL}$ for various incubation times, specifically (a) $30 \mathrm{~s}$, (b) $1 \mathrm{~min}$, (c) $3 \mathrm{~min}$, (d) $5 \mathrm{~min}$, (e) $15 \mathrm{~min}$, and (f) $30 \mathrm{~min}$.
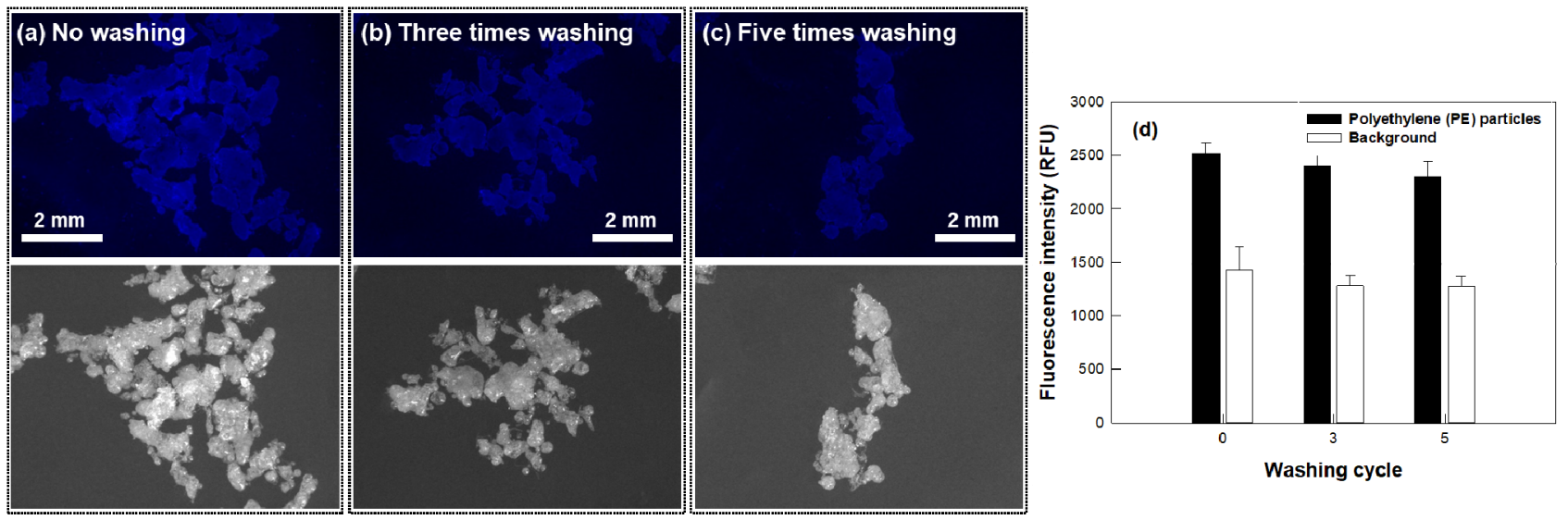

Fig. 3. (a-c) Fluorescence images (upper) and optical images (lower) of PBN-tagged polyethylene (PE) particles subjected to (a) 0 , (b) 3, and (c) 5 washing cycles with DI water. (d) Fluorescence intensities of the PE polymer and background subjected to the various numbers of washing cycles $(n=6)$.
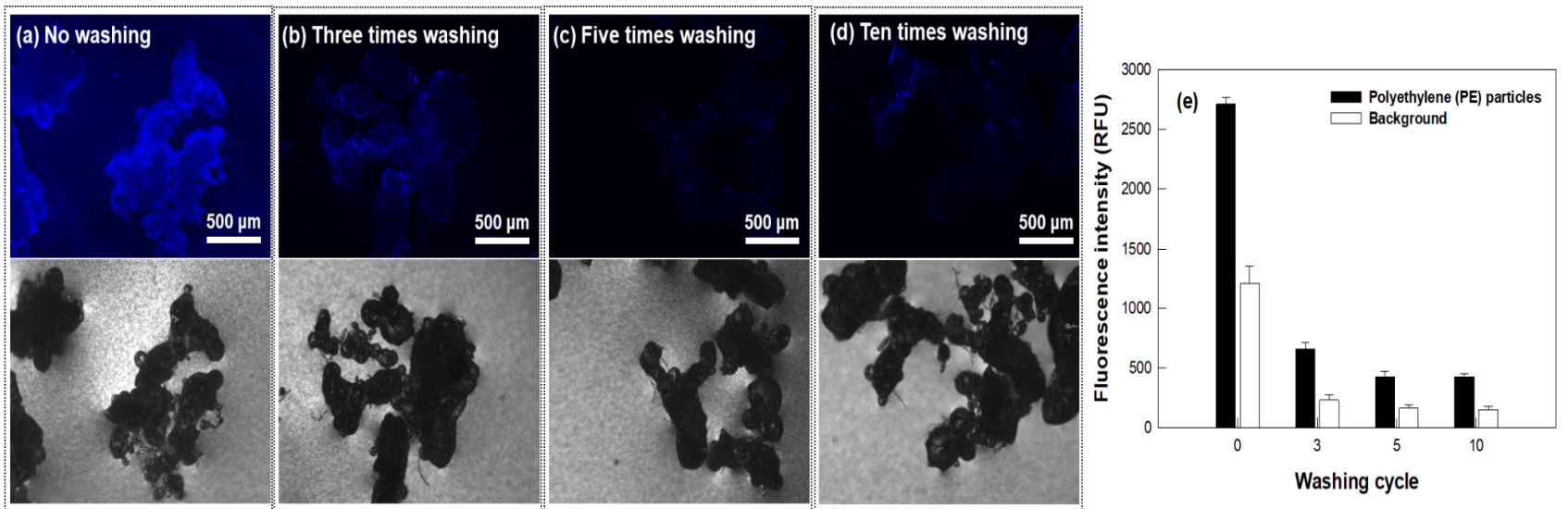

Fig.4. (a-c) Fluorescence images (upper) and optical images (lower) of PBN-tagged polyethylene (PE) particles subjected to (a) 0 , (b) 3 , (c) 5 , and (d) 10 washing cycles with $25 \%$ acetone. (e) Fluorescence intensities of the PE polymer and background subjected to the various numbers of washing cycles $(n=6)$. 

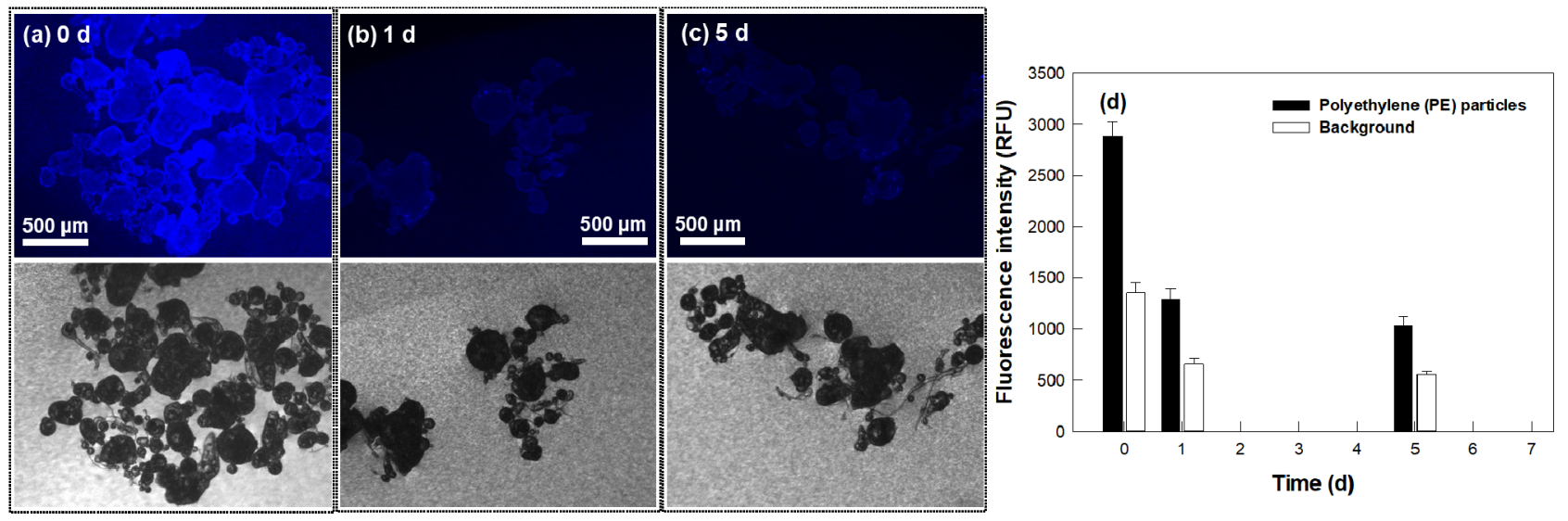

Fig. 5. (a-c) Fluorescence images (upper) and optical images (lower) of stained polyethylene (PE) polymer particles subjected to photobleaching for (a) 0 , (b) 1 , and (c) $5 \mathrm{~d}$. (d) Fluorescence intensities of the PE particles and background subjected to the photobleaching for the various indicated durations $(n=6)$.

attributable to the hydrophobicity of $\mathrm{PBN}$, causing it to be insoluble in water but miscible in acetone. The rinse-off with $25 \%$ acetone effectively exfoliated the PBN molecules from the surface of the PE polymer particles. Removal of adsorbed fluorophore is often necessary in order to reuse samples for further analysis. ${ }^{25,26)}$

The blue fluorescence of the PBN-labelled PE polymer was found to dim during the incubation of $5 \mathrm{~d}$ (Fig. 5). For example, the median fluorescence intensities of the $\mathrm{PE}$ particles and background decreased by $\sim 50 \%$ after one day (Fig.5(d)). This result was attributed to the PBN fluorophore having become degraded. The result also indicated that it is preferable to observe PE polymers within $24 \mathrm{~h}$ of dyeing them with PBN.

\subsection{Detection of microplastics in laboratory-controlled sample and commercial products using a PBN fluorophore}

A mixture of nine different polymers were visually detected in the laboratory-controlled sample. As shown in Fig. 6, the mixture of plastic particles, specifically PE, PET, PVC, PA-6, PVDC, PS, PP, PC, and PU particles, fluoresced blue light upon contact with $\mathrm{PBN}$. The locations of the polymer particles in the fluorescence images corresponded with them in the optical images. The result indicate that our screening method is able to detect the complexed samples containing a variety of polymers.

All of the tested cleanser, scrub and toothpaste consumer goods contained plastic particles, which were clearly visualized after fluorescently tagging samples of these products with PBN (Fig. 7 and S3). Different concentrations and size of the microparticles were found in different types and brands of products. Spherical particles with dimensions of $100 \mu \mathrm{m}$ were detected in cleansers $\mathrm{A}$ and $\mathrm{B}$, while irregularly shaped plastic particles were found in cleansers $C$ and D (Fig. 7 and S3). Various shapes (e.g., spherical, rounded, and irregular shapes) and sizes of particles were found in scrub and toothpaste products (Fig. 7 and S3). Irregular particles with dimensions of $\sim 300$ and $\sim 70 \mu \mathrm{m}$ were seen in scrubs $\mathrm{A}$ and $\mathrm{B}$, respectively. Meanwhile, rounded shape was found in scrub D with a size of 150-570 $\mu \mathrm{m}$. Toothpaste A contained spherical particles with dimensions of $400 \mu \mathrm{m}$.

Plastic particles were identified based on the appearance of IR bands as described in Table 1 and Fig. 8. The IR spectra of the different product types varied considerably. Cleanser A produced an IR spectrum displaying six identifiable bands, at wavenumbers of $2,918,2,845,1,461,995,842$, and $717 \mathrm{~cm}^{-1}$ (black line of Fig. 8(a)), corresponding to the frequency of PE and PP polymers. ${ }^{28-33)}$ Similarly, bands at 2,915, 2,845, $1,461,997$, and $717 \mathrm{~cm}^{-1}$ appeared in the cleanser $\mathrm{C}$ spectrum (blue line), while bands at 2,918, 2,847, 1,740 ( $\mathrm{C}=\mathrm{O}$ stretch), $1,461,995$, and $717 \mathrm{~cm}^{-1}$ appeared in the cleanser D spectrum (pink line of Fig. 8(a)). The IR spectrum of cleanser B exhibited absorption bands at 2,915, 2,845, 1,461, and 717 $\mathrm{cm}^{-1}$ (red line of Fig. 8(a)). The results indicated that microplastics found in cleansers $\mathrm{A}, \mathrm{C}$, and $\mathrm{D}$ were a mixture of PE and PP polymers, while only PE polymer was determined to have been present in cleanser B. A band at $1,740 \mathrm{~cm}^{-1}$ appeared in the cleanser D spectrum did not assign to PE and PP polymers, which is thought to be corresponded to other coexisting ingredients. 
Table 1. Absorption bands and their assignments for the acquired ATR FT-IR spectra of various consumer product samples. ${ }^{28,30-33)}$

\begin{tabular}{|c|c|c|c|}
\hline Commercial products & Category & Absorption bands $\left(\mathrm{cm}^{-1}\right)$ used for identification ${ }^{a}$ & Assignment \\
\hline \multirow[t]{4}{*}{$\begin{array}{c}\text { Cleanser } \\
(n=4)\end{array}$} & A & $\begin{array}{r}2,918(a) \\
2,845(b) \\
1,461(c) \\
995(d) \\
842(e) \\
717(f)\end{array}$ & $\begin{array}{l}\mathrm{C}-\mathrm{H} \text { stretch } \\
\mathrm{C}-\mathrm{H} \text { stretch } \\
\mathrm{CH}_{2} \text { bend } \\
\mathrm{CH}_{3} \text { rock, } \mathrm{CH}_{3} \text { bend, } \mathrm{CH} \text { bend } \\
\mathrm{CH}_{2} \text { rock, } \mathrm{C}-\mathrm{CH}_{3} \text { stretch } \\
\mathrm{CH}_{2} \text { rock }\end{array}$ \\
\hline & B & $\begin{array}{r}2,915(\mathrm{a}) \\
2,845(\mathrm{~b}) \\
1,461(\mathrm{c}) \\
717(\mathrm{~d})\end{array}$ & $\begin{array}{l}\mathrm{C}-\mathrm{H} \text { stretch } \\
\mathrm{C}-\mathrm{H} \text { stretch } \\
\mathrm{CH}_{2} \text { bend } \\
\mathrm{CH}_{2} \text { rock }\end{array}$ \\
\hline & C & $\begin{array}{r}2,915(\mathrm{a}) \\
2,845(\mathrm{~b}) \\
1,461(\mathrm{c}) \\
997(\mathrm{~d}) \\
717(\mathrm{e})\end{array}$ & $\begin{array}{l}\mathrm{C}-\mathrm{H} \text { stretch } \\
\mathrm{C}-\mathrm{H} \text { stretch } \\
\mathrm{CH}_{2} \text { bend } \\
\mathrm{CH}_{3} \text { rock, } \mathrm{CH}_{3} \text { bend, } \mathrm{CH} \text { bend } \\
\mathrm{CH}_{2} \text { rock }\end{array}$ \\
\hline & D & $\begin{array}{r}2,918(a) \\
2,847(b) \\
1,740(c) \\
1,461(d) \\
995(e) \\
717(f)\end{array}$ & $\begin{array}{l}\mathrm{C}-\mathrm{H} \text { stretch } \\
\mathrm{C}-\mathrm{H} \text { stretch } \\
\mathrm{C}=\mathrm{O} \text { stretch } \\
\mathrm{CH}_{2} \text { bend } \\
\mathrm{CH}_{3} \text { rock, } \mathrm{CH}_{3} \text { bend, } \mathrm{CH} \text { bend } \\
\mathrm{CH}_{2} \text { rock }\end{array}$ \\
\hline Commercial products & Category & Absorption bands $\left(\mathrm{cm}^{-1}\right)$ used for identification ${ }^{b}$ & Assignment \\
\hline \multirow[t]{4}{*}{$\begin{array}{l}\text { Scrub } \\
(n=4)\end{array}$} & A & $\begin{array}{r}2,922(a) \\
2,855(b) \\
1,457(c) \\
1,409(d) \\
1,162(e) \\
998(f)\end{array}$ & $\begin{array}{l}\mathrm{C}-\mathrm{H} \text { stretch } \\
\mathrm{C}-\mathrm{H} \text { stretch } \\
\mathrm{CH}_{2} \text { bend } \\
\text { Aromatic ring stretch } \\
\mathrm{CH} \text { bend, } \mathrm{CH}_{3} \text { rock, } \mathrm{C}-\mathrm{C} \text { stretch } \\
\mathrm{CH}_{3} \text { rock, } \mathrm{CH}_{3} \text { bend, } \mathrm{CH} \text { bend }\end{array}$ \\
\hline & B & $\begin{array}{r}2,925(\mathrm{a}) \\
2,859(\mathrm{~b}) \\
1,722(\mathrm{c}) \\
1,457(\mathrm{~d}) \\
993(\mathrm{e}) \\
845(\mathrm{f})\end{array}$ & $\begin{array}{l}\mathrm{CH}_{2} \text { stretch } \\
\mathrm{CH}_{2} \text { stretch } \\
\mathrm{C}=\mathrm{O} \text { stretch } \\
\mathrm{CH}_{2} \text { bend } \\
\mathrm{CH}_{3} \text { rock, } \mathrm{CH}_{3} \text { bend, } \mathrm{CH} \text { bend } \\
\mathrm{CH}_{2} \text { rock, } \mathrm{C}-\mathrm{CH}_{3} \text { stretch }\end{array}$ \\
\hline & C & $\begin{array}{l}2,944(\mathrm{a}) \\
1,722(\mathrm{~b}) \\
1,576(\mathrm{c}) \\
1,457(\mathrm{~d}) \\
1,409(\mathrm{e}) \\
1,080(\mathrm{f}) \\
995(\mathrm{~g}) \\
694(\mathrm{~h})\end{array}$ & $\begin{array}{l}\mathrm{C}-\mathrm{H} \text { stretch } \\
\mathrm{C}=\mathrm{O} \text { stretch } \\
\text { Doublet (phthalate plasticizer) } \\
\mathrm{CH}_{2} \text { bend } \\
\text { Aromatic ring stretch } \\
\text { 1,4-Disubstituted aromatic ring } \\
\mathrm{CH}_{3} \text { rock, } \mathrm{CH}_{3} \text { bend, } \mathrm{CH} \text { bend } \\
\mathrm{C}-\mathrm{Cl} \text { stretch }\end{array}$ \\
\hline & D & $\begin{array}{l}2,918(\mathrm{a}) \\
2,851(\mathrm{~b}) \\
1,740(\mathrm{c}) \\
1,464(\mathrm{~d}) \\
1,241(\mathrm{e}) \\
1,021(\mathrm{f}) \\
719(\mathrm{~g})\end{array}$ & $\begin{array}{l}\mathrm{C}-\mathrm{H} \text { stretch } \\
\mathrm{C}-\mathrm{H} \text { stretch } \\
\mathrm{C}=\mathrm{O} \text { stretch } \\
\mathrm{CH}_{2} \text { bend, } \mathrm{CH}_{3} \text { bend } \\
\mathrm{C}(=\mathrm{O}) \mathrm{O} \text { stretch } \\
\mathrm{C}-\mathrm{O} \text { stretch } \\
\mathrm{CH}_{2} \text { rock }\end{array}$ \\
\hline
\end{tabular}

\footnotetext{
${ }^{a}$ Letters in parentheses indicate absorption bands shown in Fig. 8(a)
}

${ }^{\mathrm{b}}$ Letters in parentheses indicate absorption bands shown in Fig. 8(b). 
Table 1. continued

\begin{tabular}{|c|c|c|c|}
\hline Commercial products & Category & Absorption bands $\left(\mathrm{cm}^{-1}\right)$ used for identification ${ }^{c}$ & Assignment \\
\hline \multirow[t]{4}{*}{$\begin{array}{l}\text { Toothpaste } \\
\qquad(n=4)\end{array}$} & A & $\begin{array}{r}2,925(\mathrm{a}) \\
2,848(\mathrm{~b}) \\
1,420(\mathrm{c}) \\
1,023(\mathrm{~d}) \\
959(\mathrm{e}) \\
743(\mathrm{f})\end{array}$ & $\begin{array}{l}\mathrm{C}-\mathrm{H} \text { stretch } \\
\mathrm{C}-\mathrm{H} \text { stretch } \\
\mathrm{CH}_{2} \text { bend } \\
\text { Aromatic } \mathrm{CH} \text { bend } \\
\mathrm{C}-\mathrm{C} \text { stretch } \\
\mathrm{C}-\mathrm{H} \text { bend of aromatic ring }\end{array}$ \\
\hline & B & $\begin{array}{l}2,921(\mathrm{a}) \\
2,850(\mathrm{~b}) \\
1,412(\mathrm{c}) \\
1,078(\mathrm{~d})\end{array}$ & $\begin{array}{l}\mathrm{C}-\mathrm{H} \text { stretch } \\
\mathrm{C}-\mathrm{H} \text { stretch } \\
\text { Aromatic ring stretch } \\
\text { 1,4-Disubstituted aromatic ring }\end{array}$ \\
\hline & C & $\begin{array}{l}2,925(\mathrm{a}) \\
2,852(\mathrm{~b}) \\
1,412(\mathrm{c}) \\
1,078(\mathrm{~d})\end{array}$ & $\begin{array}{l}\mathrm{C}-\mathrm{H} \text { stretch } \\
\mathrm{C}-\mathrm{H} \text { stretch } \\
\text { Aromatic ring stretch } \\
\text { 1,4-Disubstituted aromatic ring }\end{array}$ \\
\hline & D & $\begin{array}{l}2,923(\mathrm{a}) \\
2,854(\mathrm{~b}) \\
1,408(\mathrm{c}) \\
1,078(\mathrm{~d})\end{array}$ & $\begin{array}{l}\mathrm{C}-\mathrm{H} \text { stretch } \\
\mathrm{C}-\mathrm{H} \text { stretch } \\
\text { Aromatic ring stretch } \\
\text { 1,4-Disubstituted aromatic ring }\end{array}$ \\
\hline
\end{tabular}

' Letters in parentheses indicate absorption bands shown in Fig. 8(c).

Scrub A yielded six absorption bands at 2,922, 2,855, 1,457, 1,409, 1,162, and $998 \mathrm{~cm}^{-1}$ (black line of Fig.8(b)), with these results indicating the presence of PP and PC polymers. ${ }^{28,33)}$ The spectrum of scrub B showed six absorption bands: three characteristic of PP $\left(1,457,993\right.$, and $845 \mathrm{~cm}^{-1}$ ) (red line of Fig. 8(b)). Other three bands corresponded to PVC $(2,925$, 2,859 , and $\left.1,722 \mathrm{~cm}^{-1}\right)$, but $\mathrm{C}-\mathrm{Cl}$ stretching bands of the feature of PVC were not detected. Further experiments need to confirm the identification of polymer particles detected in scrub B.

Eight bands were found in the scrub $\mathrm{C}$ spectrum, which attributed to PP, PVC, and PC polymers (blue line of Fig. $\mathbf{8 ( b )}){ }^{28,30,32,33)}$ The contents of scrub D yielded an IR spectrum displaying seven distinct absorption bands (pink line of Fig. 8(b)), assigned to PE and ethylene vinyl acetate (EVA) polymers. $^{29,32)}$

Toothpaste A showed six IR absorption bands, indicative of PVC $\left(2,925,1,420\right.$, and $\left.959 \mathrm{~cm}^{-1}\right)$ and PS polymers $(2,848$, 1,023 , and $743 \mathrm{~cm}^{-1}$ ). However, $\mathrm{C}-\mathrm{Cl}$ bands were not detected in toothpaste $\mathrm{A}$, so it needs further tests to determine the particles belong to PVC. The other tested toothpaste samples (B, C, and D) showed similar IR spectra with absorbance bands at about 2,921, 2,850,1,412, and $1,078 \mathrm{~cm}^{-1}$, which were attributed to PC polymer (red, blue, and pink lines of Fig. 8(c), respectively).

The identified plastic particles in the cleanser, scrub, and toothpaste samples were for the most part expected. The PC,
PP, and PE particles were probably derived from caps, containers, and tubes that were made of these polymers. According to the product descriptions of the manufacturers, PE and PP particles were ingredients of the cleanser and scrub products usually used as exfoliants in cosmetics. ${ }^{34-36)}$ PS plastics were intentionally included in toothpaste $\mathrm{A}$ and this was attributable to the microbead contents of whitening toothpaste.

\section{Conclusions}

The PBN fluorophore simply stained plastic particles, and the particles emitted blue fluorescence upon exposure to PBN. The fluorescent tagging of the polymer particles provides visual identification of plastic pollution. Various types and sizes of polymers found in all the tested commercially available products. Most of the particles seems to be included in the products as ingredients, indicating that using personal care goods are a source of plastic pollution, particularly primary microplastics, in aquatic environment.

The simple staining process of using PBN caused minimal damage to the collected samples that will be a feature beneficial for reuse of samples for additional analyses. However, there is a possibility that the staining capability of PBN can be influenced by coexisting interferences such as surfactants in real samples. The future study will be necessary to further investigate effects of interferences on staining 

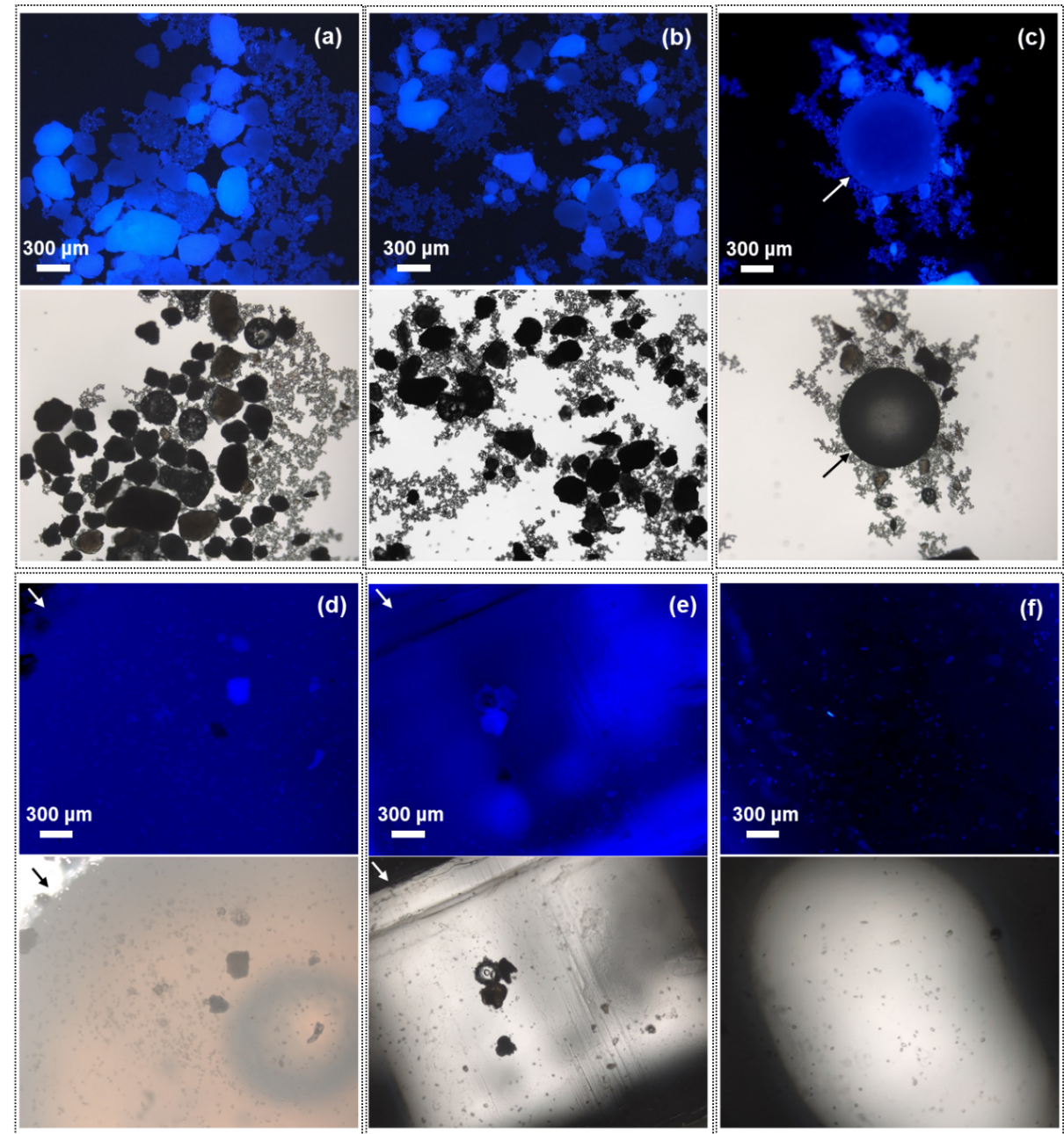

Fig. 6. Fluorescence images (upper) and optical images (lower) of a laboratory-controlled sample spiked with a mixture of polymers, specifically polyethylene (PE), poly (ethylene terephthalate) (PET), polyvinyl chloride (PVC), polyamide-6 (PA-6), polypropylene (PP), polystyrene (PS), polycarbonate (PC), polyvinylidenechloride (PVDC), and polyurethane (PU). (a) and (b) a mixture of PE, PET, PVC, PA-6, and PVDC, (c) PS (indicated as arrow), (d) PP (indicated as arrow), (e) PC, and (f) PU particles. Note that PP, PC, and PU polymers were only partially seen in microscopic images due to their large size.
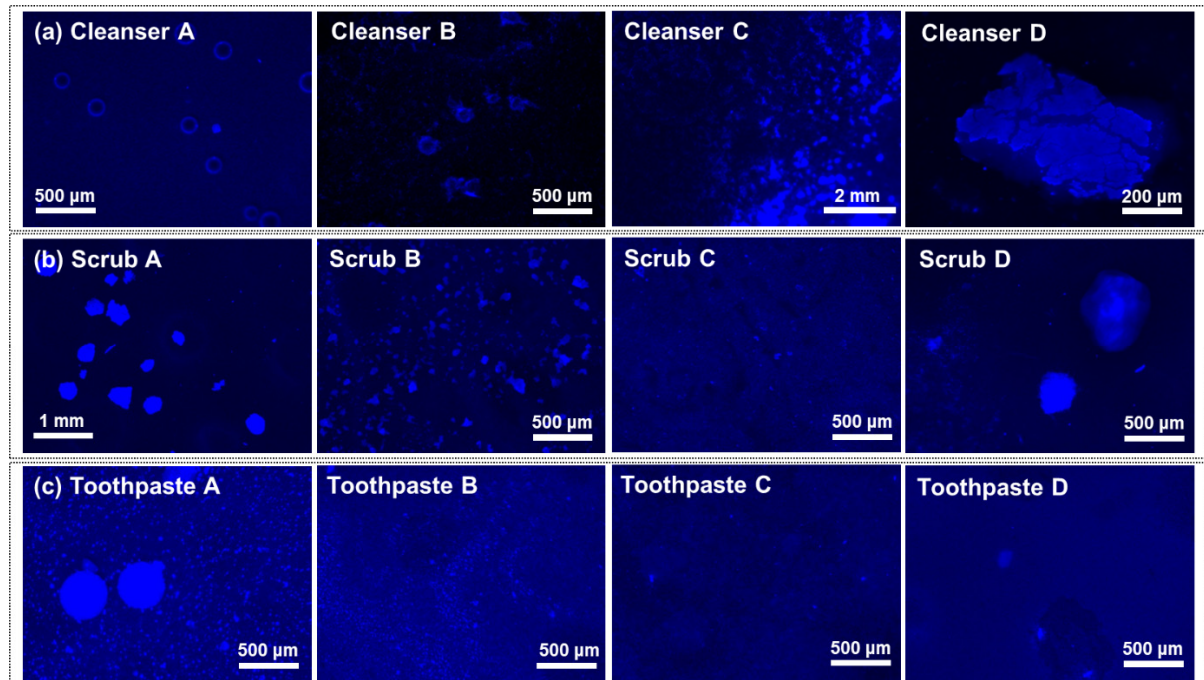

Fig.7. Fluorescence images of microplastics in samples of consumer products. (a) Upper, (b) middle, and (c) bottom rows of each panel indicate cleanser, scrub, and toothpaste samples, respectively. 

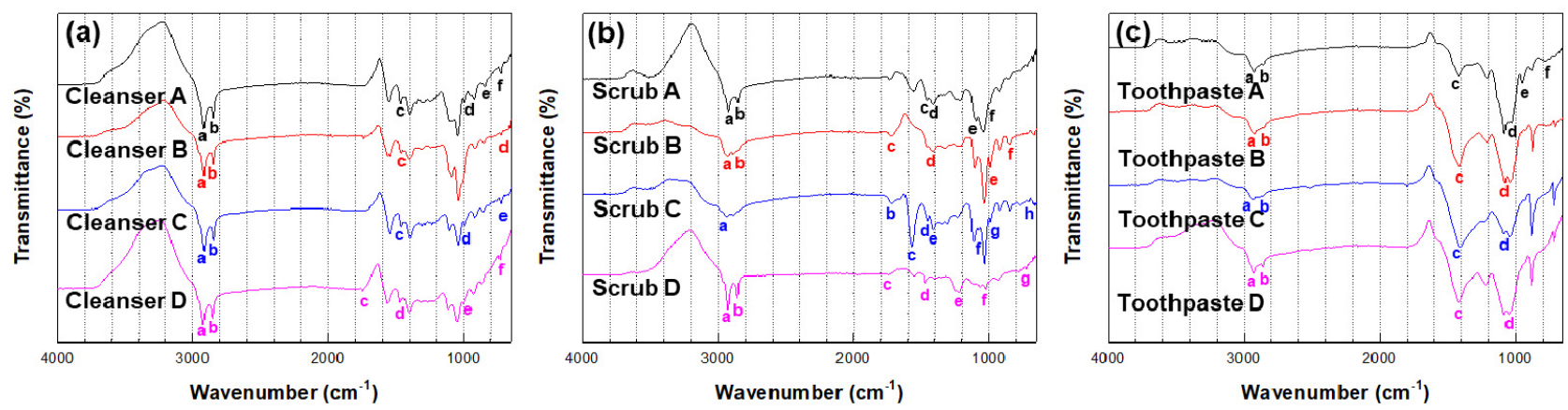

Fig. 8. ATR FT-IR spectra of various consumer products: (a) cleanser, (b) scrub, and (c) toothpaste samples. Lowercase letters indicate absorption bands of the IR spectra used for polymer identification. The respective wavenumbers of the absorption bands are listed in Table 1.

performance of PBN.

\section{Acknowledgement}

This study was supported by a 2-Year Research Grant of Pusan National University.

\section{References}

1. M. A. Browne, P. Crump, S. J. Niven, E. Teuten, A. Tonkin, T. Galloway, R. Thompson, Accumulation of microplastic on shorelines woldwide: sources and sinks, Environ. Sci. Technol., 45(21), 9175-9179(2011).

2. PlasticsEurope, Plastics-the Facts 2017, PlasticsEurope, Brussels, Belgium(2017)

3. The future of plastic, Nat. Comm., 9, 2157(2018).

4. PlasticsEurope, Plastics-the Facts 2018, PlasticsEurope, Brussels, Belgium(2018)

5. A. L. Patricio Silva, J. C. Prata, T. R. Walker, A. C. Duarte, W. Ouyang, D. Barcelo, T. Rocha-Santos, Increased plastic pollution due to COVID-19 pandemic: challenges and recommendations, Chem. Eng. J., 405, 126683(2021).

6. N. Parashar, S. Hait, Plastics in the time of COVID-19 pandemic: protector or polluter?, Sci. Total. Environ., 759, 144274(2021).

7. World Health Organization (WHO), Shortage of personal protective equipment endangering health workers worldwide, https://www.who.int/news/item/03-03-2020-shortage-of-perso nal-protective-equipment-endangering-health-workers-worldwi $\operatorname{de}(2020)$.

8. T. M. Adyel, Accumulation of plastic waste during COVID-19, Science, 369(6509), 1314-1315(2020).

9. J. C. Prata, A. L. P. Silva, T. R. Walker, A. C. Duarte, T. Rocha-Santos, COVID-19 pandemic repercussions on the use and management of plastics, Environ. Sci. Technol., 54(13), 7760-7765(2020).

10. B. Gewert, M. M. Plassmann, M. MacLeod, Pathways for degradation of plastic polymers floating in the marine environment,
Environ. Sci. Process. Impacts, 17(9), 1513-1521(2015).

11. Y. K. Song, S. H. Hong, M. Jang, G. M. Han, S. W. Jung, W. J. Shim, Combined effects of UV exposure duration and mechanical abrasion on microplastic fragmentation by polymer type, Environ. Sci. Technol., 51(8), 4368-4376(2017).

12. T. S. Hebner, M. A. Maurer-Jones, Characterizing microplastic size and morphology of photodegraded polymers placed in simulated moving water conditions, Environ. Sci. Process. Impacts, 22(2), 398-407(2020).

13. I. E. Napper, B. F. R. Davies, H. Clifford, S. Elvin, H. J. Koldewey, P. A. Mayewski, K. R. Miner, M. Potocki, A. C. Elmore, A. P. Gajurel, R. C. Thompson, Reaching new heights in plastic pollution-preliminary findings of microplastics on mount Everest, One Earth, 3(5), 621-630(2020).

14. M. Lehtiniemi, S. Hartikainen, P. Näkki, J. Engström-Öst, A. Koistinen, O. Setälä, Size matters more than shape: ingestion of primary and secondary microplastics by small predators, Food Webs, 17, e00097(2018).

15. A. Cózar, F. Echevarría, J. I. González-Gordillo, X. Irigoien, B. Ubeda, S. Hernández-León, A. T. Palma, S. Navarro, J. García-de-Lomas, A. Ruiz, M. L. Fernández-de-Puelles, C. M. Duarte, Plastic debris in the open ocean, Proc. Natl. Acad. Sci. USA, 111(28), 10239-10244(2014).

16. M. Eriksen, L. C. M. Lebreton, H. S. Carson, M. Thiel, C. J. Moore, J. C. Borerro, F. Galgani, P. G. Ryan, J. Reisser, Plastic pollution in the world's oceans: more than 5 trillion plastic pieces weighing over 250,000 tons afloat at sea, PLoS One, 9(12), e11913(2014).

17. C. Campanale, C. Massarelli, I. Savino, V. Locaputo, V. F. Uricchio, A detailed review study on potential effects of microplastics and additives of concern on human health, Int. J. Environ. Res. Public Health, 17(4), 1212(2020).

18. P. Farrell, K. Nelson, Trophic level transfer of microplastic: Mytilus edulis (L.) to Carcinus maenas (L.), Environ. Pollut., 177, 1-3(2013).

19. A. D. Gray, J. E. Weinstein, Size- and shape-dependent effects of microplastic particles on adult daggerblade grass shrimp (Palaemonetes pugio), Environ. Toxicol. Chem., 36(11), 3074-3080(2017).

20. A. Batel, F. Linti, M. Scherer, L. Erdinger, T. Braunbeck, 
Transfer of benzo[a]pyrene from microplastics to Artemia nauplii and further to zebrafish via a trophic food web experiment: CYP1A induction and visual tracking of persistent organic pollutants, Environ. Toxicol. Chem., 35(7), 1656-1666(2016).

21. S. Hossain, M. A. Rahman, M. A. Chowdhury, S. K. Mohonta, Plastic pollution in Bangladesh: a review on current status emphasizing the impacts on environment and public health, Environ. Eng. Res., 26(6), 200535(2021).

22. M. Paredes, R. Viteri, T. Castillo, C. Caminos, C. E. Enyoh, Microplastics from degradation of tires in sewer networks of the city of Riobamba, Ecuador, Environ. Eng. Res., 26(5), 200276(2021).

23. E.-H. Lee, S. Lee, Y. Chang, S.-W. Lee, Simple screening of microplastics in bottled waters and environmental freshwaters using a novel fluorophore, Chemosphere, 285, 131406(2021).

24. J. C. Prata, J. P. da Costa, A. C. Duarte, T. Rocha-Santos, Methods for sampling and detection of microplastics in water and sediment: a critical review, Trac-Trends. Anal. Chem., 110, 150-159(2019).

25. G. Erni-Cassola, M. I. Gibson, R. C. Thompson, J. A. Christie-Oleza, Lost, but found with Nile Red: a novel method for detecting and quantifying small microplastics (1 $\mathrm{mm}$ to $20 \mu \mathrm{m})$ in environmental samples, Environ. Sci. Technol., 51(23), 13641-13648(2017).

26. T. Maes, R. Jessop, N. Wellner, K. Haupt, A. G. Mayes, A rapid-screening approach to detect and quantify microplastics based on fluorescent tagging with Nile Red, Sci. Rep., 7, 44501(2017).

27. E. G. Karakolis, B. Nguyen, J. B. You, C. M. Rochman, D. Sinton, Fluorescent dyes for visualizing microplastic particles and fibers in laboratory-based studies, Environ. Sci. Technol. Lett., 6(6), 334-340(2019).

28. M. R. Jung, F. D. Horgen, S. V. Orski, C. V. Rodriguez, K. L. Beers, G. H. Balazs, T. T. Jones, T. M. Work, K. C. Brignac, S. J. Royer, K. D. Hyrenbach, B. A. Jensen, J. M. Lynch, Validation of ATR FT-IR to identify polymers of plastic marine debris, including those ingested by marine organisms, Mar. Pollut. Bull., 127, 704-716(2018).

29. R. C. Asensio, M. S. A. Moya, J. M. de la Roja, M. Gómez, Analytical characterization of polymers used in conservation and restoration by ATR-FTIR spectroscopy, Anal. Bioanal. Chem., 395(7), 2081-2096(2009).

30. I. Noda, A. E. Dowrey, J. L. Haynes, C. Marcott, Group frequency assignments for major infrared bands observed in common synthetic polymers, Physical properties of polymers Handbook, J. E. Mark(Ed.), Springer New York, New York, United States, pp. 395-406(2007).

31. K. Nishikida, J. Coates, Infrared and Raman analysis of polymers, Handbook of Plastics Analysis, 1st ed., Marcel
Dekker, Inc., New York, United States, pp. 186-316(2003).

32. G. A. L. Verleye, N. P. G. Roeges, M. O. De Moor, Easy identification of plastics and rubbers, Smithers Rapra Technology, Shropshire, United Kingdom(2001).

33. G. Mitchell, F. France, A. Nordon, P. L. Tang, L. T. Gibson, Assessment of historical polymers using attenuated total reflectance-Fourier transform infra-red spectroscopy with principal component analysis, Herit. Sci., 1, 28(2013).

34. L. M. Hernandez, N. Yousefi, N. Tufenkji, Are there nanoplastics in your personal care products?, Environ. Sci. Technol. Lett., 4(7), 280-285(2017).

35. C. Lassen, S. Foss Hansen, K. Magnusson, F. Norén, N. I. Bloch Hartmann, P. Rehne Jensen, T. G. Nielsen, A. Brinch, Microplastics-occurrence, effects and sources of releases to the environment in Denmark, DTU Library, Copenhagen, Denmark(2015).

36. L. S. Fendall, M. A. Sewell, Contributing to marine pollution by washing your face: microplastics in facial cleansers, Mar. Pollut. Bull., 58(8), 1225-1228(2009).

\section{Declaration of Competing Interest}

The authors declare that they have no known competing financial interests or personal relationships that could have appeared to influence the work reported in this paper.

\section{Authors and Contribution Statement}

\section{Eun-Hee Lee}

Department of Microbiology, Pusan National University, Republic of Korea, Assistant Professor, ORCiD (10 0000-0002-4388-8092: Conceptualization, Methodology, Visualization, Data analysis, Investigation, Writing - original draft, Writing - review and editing.

\section{Sangwon Lee}

Department of Fine Chemistry, Seoul National University of Science and Technology, Republic of Korea, MS, ORCiD(1) 0000-0002-4990-7442: Investigation, Methodology.

\section{Seung-Woo Lee}

Department of Fine Chemistry, Seoul National University of Science and Technology, Republic of Korea, Department of Nano \& Bioengineering, Seoul National University of Science and Technology, Republic of Korea, Assistant Professor, ORCiD(1) 0000-0003-4627-4712: Supervision, Conceptualization, Writing review and editing. 